$10-1-2014$

\title{
Allied Health Student Clinical Placements in Residential Aged Care Facilities: Staff Opinions, Attitudes, and Support Needs
}

\author{
Catherine Johnston \\ The University of Newcastle \\ Clint Newstead \\ The University of Newcastle \\ Sarah Walmsley \\ The University of Newcastle \\ Lesley MacDonald \\ The University of Newcastle
}

Follow this and additional works at: https://nsuworks.nova.edu/ijahsp

Part of the Medicine and Health Sciences Commons

\section{Recommended Citation}

Johnston C, Newstead C, Walmsley S, MacDonald L. Allied Health Student Clinical Placements in Residential Aged Care Facilities: Staff Opinions, Attitudes, and Support Needs. The Internet Journal of Allied Health Sciences and Practice. 2014 Oct 01;12(4), Article 11.

This Manuscript is brought to you for free and open access by the College of Health Care Sciences at NSUWorks. It has been accepted for inclusion in Internet Journal of Allied Health Sciences and Practice by an authorized editor of NSUWorks. For more information, please contact nsuworks@nova.edu. 


\title{
Allied Health Student Clinical Placements in Residential Aged Care Facilities: Staff Opinions, Attitudes, and Support Needs
}

\begin{abstract}
Purpose: As the population ages, the incidence and prevalence of chronic health issues requiring allied health management is increasing. Currently, there is an undersupply of appropriately skilled allied health professionals working in aged care. This has also been identified as a setting in which many beginning health practitioners are reluctant to seek employment. In order to address this workforce shortage, it is imperative that students are prepared for a possible future career within aged care facilities. Early clinical experience within this setting may increase student confidence, raise awareness of the need for services, and encourage students to consider working in aged care. At present, student clinical placements within aged care facilities are limited, potentially contributing to difficulties addressing workforce needs. The reasons for the lack of clinical placements and the relative contribution of the opinions, attitudes, training, and support needs of staff are unknown. The purpose of this study was to investigate the opinions, attitudes, support, and training needs of physiotherapists, dieticians, and managers working in residential aged care regarding allied health professional student clinical placements. Method: A written survey of allied health professionals (dieticians and physiotherapists, $n=26)$ and managers $(n=40)$ working in residential aged care was conducted. Responses were analysed using qualitative and quantitative methods. Results: Participants had generally positive attitudes towards student placements in residential aged care. Managers were significantly more positive regarding the scope for student clinical placements within their facilities than allied health professionals $(p<0.05)$. The biggest barrier to student placements identified by both managers and allied health professionals was the nature of employment of allied health professionals in the sector. Participating allied health professionals also indicated that they required specific training in student supervision and the provision of clinical education. Conclusion: The attitudes and opinions of allied health professionals and managers did not appear to contribute to a lack of allied health professional student placements in aged care facilities. The main barriers to placement were the nature of allied health professional employment and a lack of staff experience in supervising students on clinical placement. Specific training and mentoring of allied health professionals may facilitate increased student placement capacity in the aged care setting.
\end{abstract}




\title{
TAHSP:-
}

The Internet Joưnal of Allied Health Sciences and Practice

A Peer Reviewed Publication of the College of Health Care Sciences at Nova Southeastern University

Dedicated to allied health professional practice and education

http://ijahsp.nova.edu Vol. 12 No. 4 ISSN 1540-580X

\section{Allied Health Student Clinical Placements in Residential Aged Care Facilities: Staff Opinions, Attitudes, and Support Needs}

\author{
Catherine Johnston, $\mathrm{PhD}^{1}$ \\ Clint Newstead, BPhysio (Hons) ${ }^{2}$ \\ Sarah Walmsley, $\mathrm{PhD}^{3}$ \\ Lesley MacDonald - Wicks, $\mathrm{PhD}^{4}$
}

1. Lecturer, Discipline of Physiotherapy, School of Health Sciences, The University of Newcastle, Callaghan, New South Wales

2. Clinical Educator, Conjoint Lecturer, Discipline of Physiotherapy, School of Health Sciences, The University of Newcastle, Callaghan, New South Wales

3. Conjoint Lecturer, Discipline of Physiotherapy, School of Health Sciences, The University of Newcastle, Callaghan, New South Wales

4. Senior Lecturer, Discipline of Nutrition and Dietetics, School of Health Sciences, The University of Newcastle, Callaghan, New South Wales

Australia

CITATION: Johnston C, Newstead C, Walmsley S, MacDonald L. Allied Health Student Clinical Placements in Residential Aged Care Facilities: Staff Opinions, Attitudes, and Support Needs. The Internet Journal of Allied Health Sciences and Practice. Oct 2014. Volume 12 Number 4.

\begin{abstract}
Purpose: As the population ages, the incidence and prevalence of chronic health issues requiring allied health management is increasing. Currently, there is an undersupply of appropriately skilled allied health professionals working in aged care. This has also been identified as a setting in which many beginning health practitioners are reluctant to seek employment. In order to address this workforce shortage, it is imperative that students are prepared for a possible future career within aged care facilities. Early clinical experience within this setting may increase student confidence, raise awareness of the need for services, and encourage students to consider working in aged care. At present, student clinical placements within aged care facilities are limited, potentially contributing to difficulties addressing workforce needs. The reasons for the lack of clinical placements and the relative contribution of the opinions, attitudes, training, and support needs of staff are unknown. The purpose of this study was to investigate the opinions, attitudes, support, and training needs of physiotherapists, dieticians, and managers working in residential aged care regarding allied health professional student clinical placements. Method: A written survey of allied health professionals (dieticians and physiotherapists, $n=26)$ and managers $(n=40)$ working in residential aged care was conducted. Responses were analysed using qualitative and quantitative methods. Results: Participants had generally positive attitudes towards student placements in residential aged care. Managers were significantly more positive regarding the scope for student clinical placements within their facilities than allied health professionals $(p<0.05)$. The biggest barrier to student placements identified by both managers and allied health professionals was the nature of employment of allied health professionals in the sector. Participating allied health professionals also indicated that they required specific training in student supervision and the provision of clinical education. Conclusion: The attitudes and opinions of allied health professionals and managers did not appear to contribute to a lack of allied health professional student placements in aged care facilities. The main barriers to placement were the nature of allied health professional employment and a lack of staff experience in supervising students on
\end{abstract}


clinical placement. Specific training and mentoring of allied health professionals may facilitate increased student placement capacity in the aged care setting.

\section{INTRODUCTION}

The Australian population is aging with the past decades seeing an increase in those aged over 65 years and a rapid rise in those living beyond $85.1,2$ Many of those living to an older age have chronic illnesses and degenerative conditions, placing an increased demand on the healthcare system..$^{3-5}$ Issues such as falls, poor mobility, and neurological impairments are common in the elderly.6,7 The prevalence of malnutrition, with resulting reduction in quality of life (QoL), poor wound healing, and increased morbidity is also high. Patient populations at greatest risk are the oldest, the frail, and those requiring the highest levels of care. 8,9 Management of these issues and an emphasis on the promotion of optimal functional ability and general wellbeing requires the involvement of allied health professionals such as physiotherapists and dietitians. ${ }^{10}$

The role of physiotherapy in aged care is well recognised with physiotherapy intervention resulting in reduction of falls and improvements in mobility, strength, balance, and exercise capacity. ${ }^{11-13}$ Similarly, the involvement of dieticians in the aged care setting is essential. Dietetic management, including appropriate use of nutritional supplements and the implementation of comprehensive screening, assessment and intervention, results in improved patient outcomes. ${ }^{8,14-16}$

Currently, there is an undersupply of appropriately skilled allied health professionals employed in aged care, a situation that will worsen as the median age of the population rises.5,9,17 In addition, aged care has been identified as an area in which many beginning health practitioners are reluctant to seek employment. ${ }^{17}$ The exposure of physiotherapy and dietetic students to clinical placements in the aged care setting during their entry-level training may ameliorate these issues. Early clinical experience within this sector may increase student confidence, raise awareness of the need for services, and encourage students to consider working in the aged care sector. ${ }^{17}$ At present, student placements within aged care facilities are limited, and many students rely on gaining aged care experience in non-specific settings such as hospitals and private practices. It is not clear why there are so few physiotherapy and dietetic student placements within aged care facilities and the relative contribution of the opinions, attitudes, training, and support needs of staff within these facilities to the lack of student placements is unknown.

The purpose of this study was to investigate the attitudes of physiotherapists, dieticians, and health service managers working within residential aged care towards allied health professional student clinical placements in this sector. This study also explored the training and support that might be required to enable student placements within these facilities.

\section{METHOD}

\section{Study Design}

The study was a cross sectional design using two anonymous written surveys. Ethics approval for this study was granted by the Human Research Ethics Committee of the University of Newcastle.

\section{Participants}

Participants were allied health professionals (physiotherapists and dieticians) and managers currently employed by or contracted to residential aged care facilities. Facilities located within the Hunter Valley, Central Coast, and Mid-North Coast regions of New South Wales were identified using the Australian Government "My Aged Care" website. ${ }^{18}$ Facilities listing physiotherapy or dietetic services provided permanently on-site or on a casual basis were recorded. If this information was not available on the "My Aged Care" website, the specific website for the aged care facility site was accessed (if available) to determine the level of allied health professional service. A database of identified facilities with potential physiotherapy and/or dietetic staffing was developed. Facility managers $(n=93)$, physiotherapists $(n=78)$ and dieticians $(n=16)$ were invited to participate. There were no exclusion criteria.

\section{Data Collection Process}

Information sheets, surveys, and pre-paid return envelopes were sent to the managers and allied health professionals of aged care health sites. A single allied health professional and manager from each site was invited to participate. Surveys were completed anonymously; however, participants could provide contact details for future correspondence. Completion and return of the survey constituted informed consent.

\section{Survey Instrument}

As no published or validated survey tool existed, surveys were developed for the study (Appendices A and B). One survey was designed for allied health professionals (physiotherapists and dieticians) and the other for managers. Each survey consisted of 14 questions in five categories: i) participant characteristics, ii) current involvement in placements, iii) scope for future 
placements within their facility, iv) opinions regarding placements within aged care facilities (advantages, disadvantages and barriers) and v) perceived support requirements for placements. Both surveys also contained free text sections for participants to provide additional comments.

\section{Data Analysis}

All data were collated and analysed using the Statistical Package for the Social Sciences (SPSS version 21.0, IBM Corp, Armonk, NY). All closed categorical responses were analysed descriptively using frequencies and percentages. Chi-square analysis was performed to compare the categorical responses from the allied health professionals and managers and the significance level was set at 0.05 . Simple content analysis was performed for the written responses relating to opinions toward student clinical placements in aged care and the perceived training and support needs. Comments were independently coded by two different investigators based on recurring regularities; and, final themes decided on via a process of convergence.

\section{RESULTS}

\section{Response Rate}

Of the total 187 surveys initially distributed, 66 were returned, with an overall response rate of $35 \%$. The individual number of responses by profession was $25(32 \%)$ physiotherapists, one (6\%) dietician and $40(43 \%)$ facility managers.

\section{Participant Characteristics}

The majority of the participating managers were from a health professional background (85\%), with an average of 13 years experience $(S D$ 9, Range $=2-30)$ as facility managers. Characteristics of participating allied health professionals are presented in Table 1

\begin{tabular}{|c|c|}
\hline Participant Characteristic & $n(\%)$ \\
\hline \multicolumn{2}{|l|}{ Gender } \\
\hline Female & $16(61.54)$ \\
\hline Male & $10(38.46)$ \\
\hline \multicolumn{2}{|l|}{ Professional background } \\
\hline Nutrition and dietetics & $1(3.85)$ \\
\hline Physiotherapy & $25(96.15)$ \\
\hline \multicolumn{2}{|l|}{ Years since qualification } \\
\hline$<1$ year & $1(3.85)$ \\
\hline $1-4$ years & $3(11.54)$ \\
\hline $5-10$ years & $3(11.54)$ \\
\hline $11-15$ years & $2(7.69)$ \\
\hline$>15$ years & $17(65.38)$ \\
\hline \multicolumn{2}{|l|}{ Student supervision } \\
\hline Currently supervising & $5(19.23)$ \\
\hline Never supervised & $14(53.85)$ \\
\hline
\end{tabular}




\section{Current Involvement in Clinical Placements}

Managers were asked to indicate if their site offered clinical placements for any discipline. Of the participants, $37(93 \%)$ stated that clinical placements were occurring within their facility. Placements most commonly existed for nursing students $(n=26,70 \%)$ followed by medical students $(n=7,19 \%)$. Three facilities offered physiotherapy placements and three offered dietetic placements. Allied health professionals were asked to explain why their facilities were not involved in student training or support. If allied health professionals indicated that they had no current or previous involvement in student supervision they were asked to comment on why. The main themes emerging from these comments are displayed in Table 2.

Table 2. Reasons Allied Health Professionals Did Not Provide Training or Support for Students

\begin{tabular}{|l|l|}
\hline Theme & Illustrative comments \\
\hline Employment conditions & $\begin{array}{l}\text { 'I work as a contractor/casual with varied hours } \\
\text { in varied facilities.' } \\
\text { 'Only work part-time.' } \\
\text { Suitability of facility/caseload limited hours: unable to give student a } \\
\text { full-time placement.' }\end{array}$ \\
\hline 'Setting not appropriate.' \\
'Mainly assessment work, limited treatments,' \\
'My role is essentially as a consultant to advise \\
re. programmes/pain management,'
\end{tabular}

\section{Opinions Regarding Advantages, Disadvantages and Scope for Clinical Placements in Aged Care Facilities}

The opinions of aged care facility managers and allied health professionals regarding the advantages, disadvantages, barriers, and scope for clinical placements are presented in Table 3. There was no significant difference between managers and allied health professionals in reporting whether they thought there were advantages $(p>0.05)$, or barriers $(p>0.05)$ to placements in aged care. More allied health professionals than managers indicated there were disadvantages; however, this was not statistically significant $(p>0.05)$. There was a significant difference $(p>0.05)$ between managers and allied health professionals in their opinion about the scope of their facility to provide allied health professional student placements. 
Table 3. Manger and Allied Health Professional Opinion of Student Training

\begin{tabular}{|c|c|c|c|}
\hline \multirow[b]{2}{*}{$\begin{array}{l}\text { Regarding student clinical } \\
\text { placements in aged care }\end{array}$} & \multicolumn{2}{|c|}{ 'Yes' response } & \multirow[b]{2}{*}{$p$-value } \\
\hline & $\begin{array}{l}\text { AHP† } \\
n(\%)\end{array}$ & $\begin{array}{c}\text { Manager } \\
\mathrm{n}(\%)\end{array}$ & \\
\hline Are there advantages? & $25(96.15)$ & $38(95.00)$ & 1.00 \\
\hline Are there disadvantages? & $13(50.00)$ & $10(25.00)$ & 0.06 \\
\hline Are there barriers? & $16(61.54)$ & $19(47.40)$ & 0.31 \\
\hline $\begin{array}{l}\text { Is there scope for placements in your } \\
\text { facility? }\end{array}$ & $11(42.31)$ & $33(82.50)$ & 0.003 \\
\hline
\end{tabular}

†Allied Health professional

Six major themes emerged from the written survey responses:

Theme 1: Employment Conditions

Allied health professionals frequently reported that they were unable to adequately supervise students due to employment constraints, often being employed on a contract or part-time basis and/or working across multiple sites.

"Lack of continuous supervision, frequently staffed by part-time professionals."

"I move around to multiple facilities. If the physio worked at one workplace, that would be more suitable for students."

Likewise, facility managers also identified the nature of allied health professional employment as a barrier to student placements.

"Lack of full-time allied health professionals."

Theme 2: Workforce Preparation

The majority of allied health professionals indicated that student placements would have a positive influence on preparedness to work in this field. Participants generally agreed that clinical experience in aged care settings would consolidate knowledge and refine skills necessary for the assessment and treatment of elderly patients. Many also suggested that as the population ages there is an increasing need to focus on health care delivery within the aged care sector.

"Growing need for high level training in ...aged care."

This opinion was generally reflected in the written comments of the facility managers, who also acknowledged the increasing need for skilled allied health professionals within their work place.

"Many allied health professionals will be finding their employment in aged related services - for many students under 35 years of age, their exposure to the elderly in normal life is limited."

\section{Theme 3: Student Attitudes}

Many of the participants indicated that undertaking a student placement in an aged care facility had the potential to either positively or negatively influence student attitudes. Most of the written comments suggested that this influence would be positive, resulting in an increased desire to seek employment in this sector in the future. Several allied health professionals suggested that students may not consider future employment in aged care if they are not aware of the role of and demand for their profession in this field.

"Encourage allied health students to consider a career in aged care."

"It can ignite a desire to work in and make a difference to the older population. 
In contrast to this, some allied health professionals indicated that clinical placements situated within the aged care setting could negatively influence student attitudes, subsequently deterring them from working in the aged care sector. The participants suggesting this indicated that students would generally not find the placement challenging or stimulating and may be discouraged by repetitive assessment and treatment techniques and slow rates of patient improvement.

"Early exposure to this unfavourable area may prevent students from considering aged care as a future area of work..."

'Students seem to find it boring and repetitive at times.'

Two of the facility managers perceived that pre-existing student attitudes towards working in this setting may be problematic and a possible barrier for future placements within aged care facilities.

“...student enthusiasm, motivation, resistance, hostility (towards) placement."

"Ageist attitudes that make aged care seem unattractive."

\section{Theme 4: Knowledge and Skills}

The majority of participants reported that acquiring new knowledge and skills was an advantage of student placements within the aged care sector. The written responses suggested that gaining clinical experience in this area would result in an improvement in the student's theoretical and procedural knowledge. More specifically, allied health professionals and managers of aged care facilities agreed that experience in these settings would teach students about the ageing process and offer an opportunity to further develop communication, assessment, treatment, and teamwork skills.

"Help improve assessment and critical thinking skills."

“...first-hand experience dealing with the elderly and their challenges e.g. dementia behaviours."

In addition, two of the participating managers suggested that student placements within their facilities could provide an opportunity for other staff to improve their knowledge and skills.

"Opportunities to engage...other staff (in learning)."

"Nurses will gain additional knowledge."

\section{Theme 5: Caseload}

A recurring theme in the allied health professionals' responses was caseload suitability. Opinions of the allied health professionals appeared to be equally divided regarding the variety of clinical experiences and the complexity in managing elderly patients. Some allied health professionals and facility managers implied that undertaking a placement within the aged care setting would be a good means of challenging the student's clinical reasoning and developing practical skills.

"Generally residents in Aged Care facilities have co-morbidities which provide the students with a broad scope for developing a variety of treatment plans."

"Aged care encompasses many aspects of physiotherapy e.g. falls prevention... exercise programmes...treatment of acute injuries... management of chronic conditions..."

It was also suggested that the complex needs of the elderly patient may impact negatively on the student's ability to learn in this environment.

"...clients will more commonly have dementia issues affecting communication and cooperation; the needs of many clients could be complex which may be confusing..."

"...hands on treatment is limited...clinical reasoning is very simple too... poor carry-over with residents due to dementia/cognitive issues." 


\title{
Theme 6: Service Provision
}

Overall, both allied health professionals and managers perceived that student placements in the aged care setting would have a positive influence on service delivery leading to increased allied health professional services being provided for residents. This theme was more apparent in the written responses of facility managers than the allied health professionals.

\author{
"Advantageous for both residents and students - residents are assisted with services/students receive \\ education about the ageing process." \\ "Extra care/treatments for residents..." \\ "Residents will benefit/better care..."
}

\section{Support Needs for Clinical Placements}

Several of the participating allied health professionals indicated that they would require formal training prior to supervising students. This training should focus on two areas: teaching in the clinical setting and assessment procedures. In addition to this, the majority of allied health professionals indicated that regular contact from university academic staff, via telephone or site visit, would be necessary to provide students with on-going support and assist in their supervisory role. It was suggested that training could be delivered in electronic or hard-copy format.

Facility manager comments focussed mainly on support needs rather than training. The majority of participating facility managers indicated that support in the form of financial recompense or a dedicated clinical supervisor funded by tertiary institutions would be necessary for future placements to occur.

\section{DISCUSSION}

This study is the first to explore the attitudes and opinions of allied health professionals and aged care facility managers towards student placements in residential aged care. The study investigated the views of managers, physiotherapists, and dieticians working within aged care facilities and also explored the perceived training and support needs required for the establishment and maintenance of student placements. The main findings were that while both the surveyed managers and allied health professionals were positive about student placements in aged care and perceived many advantages, barriers existed relating to staffing and the employment conditions. Participating allied health professionals were experienced in their clinical roles, but less experienced with teaching and assessing students in terms of years of experience.

While managers indicated that there were a number of nursing and medical placements occurring within the surveyed aged care facilities, there were few placements offered to physiotherapy and dietetic students. Participating allied health professionals acknowledged aged care as an area requiring appropriately skilled physiotherapists and dieticians and emphasised the importance of student placements within aged care in addressing workforce shortages. Allied health professionals and facility managers were in general agreement as to the reasons why so few placements currently existed for physiotherapy and dietetic students. It was reported that the biggest barrier was the nature of allied health professional employment (contract, part-time basis) resulting in an inability to provide adequate teaching and supervision.

It is possible that sites staffed by allied health professionals on a contract or part-time basis may still be able to participate in student clinical education. In order for this to occur, further investigation into more innovative placement models is necessary. For example, it may be possible for students to undertake a placement on a part time basis for a longer duration or for the student to undertake a single placement within two or more different aged care facilities. ${ }^{19}$

The majority of managers and allied health professionals were positive regarding physiotherapy and dietetic student placements within the aged care setting. Managers however, were significantly more positive than allied health professionals. The reason for this may be that the allied health professionals have a greater understanding of what is involved in supervising a student in their discipline and are more aware of the associated barriers. Many managers perceived that physiotherapy and dietetic student placements would have a positive impact on the provision of services to residents at their facility. While this is encouraging, it is possible that facility managers, some who may be inexperienced, are unaware of time and energy required to mentor students.

Managers also differed from the participating allied health professionals in that they indicated that financial compensation or funding for a dedicated supervisor would be required for placements to occur within their facility. In contrast, support needs reported by allied health professionals related mainly to the need for formal training on clinical teaching and assessment in order to facilitate future student placements. This supports the finding that the surveyed allied health professionals were very 
experienced in their clinical roles, but lacked experience in teaching and supervising students. Although the participating allied health professionals perceived lack of training as a potential barrier to future placements, this may be easily addressed. At present many tertiary institutions offer training sessions in the form of seminars or workshops for prospective or inexperienced supervisors. In order to make these sessions relevant to those working in aged care, specific learning objectives or training needs would need to be explored. Most participants indicated that targeted training on teaching strategies and assessment in the clinical setting would be necessary to best prepare them for supervising a student.

The main limitation of this study was the low response rate to the written survey from both allied health professionals and facility managers. This may be due to reliance on the Australian Government "My Aged Care" website as a means of identifying participants..$^{18}$ It may be that this website does not contain the most up-to-date information about all aged care facilities. Also, while many aged care facilities were identified, it is not known if each mailed survey reached the intended recipient, especially given the possibility that some staff work across multiple sites and on a contract or part-time basis. Individual telephone contact with each site to confirm allied health professional contact details may have been a means of increasing response rate. Despite the low response rate, the findings of this study form a preliminary investigation of this under-researched but important issue. Another limitation of the study is that it only included two allied health professional discipline: physiotherapy and dietetics. Future research should focus on investigating opinions, attitudes, and support needs relating to student placements amongst a wider professional base and with a larger sample size.

In conclusion, it does not appear that the attitudes and opinions of allied health professionals and managers working in aged care were the major contributors to the lack of student clinical placements in this setting. The most important factor was the employment conditions of allied health professionals in aged care. Allied health staff are mostly employed on a part-time or contract basis which limits their ability to provide adequate supervision, teaching, and assessment time required for student placements. An additional consideration is the current lack of allied health professional experience and training in clinical supervision. Additional allied health professional funding and targeted training for supervisors is required to increase placement capacity within the aged care sector and prepare students for work within this area of need.

\section{REFERENCES}

1. Richmond RL. The changing face of the Australian population: growth in centenarians. Med J Aust. 2008;188:720-3. [PMID:18558896]

2. Population by age and sex, Australian states and territories [Internet]. Australian Bureau of Statistics. c2011 [cited 2013 Dec 4]. Available from: http://www.abs.gov.au/ausstats/abs@.nsf/mf/3101.0.

3. Rizza A, Kaplan V, Senn O, Roseman T, Bhend H, Tandjung R. Age and gender related prevalence of multimorbidity in primary care: the Swiss fire project. BMC Fam Pract. 2012;13:113. [PMID: 23181753]

4. Gilbert AL, Caughey GE, Vitry Al, Clark A. Ageing well: improving the management of patients with multiple chronic health problems. Australas J Ageing. 2011;30:32-7. [PMID:22032768]

5. Health workforce in Australia and factors for current shortages 2009 [Internet]. National Health Workforce Taskforce. c2009 [cited 2013 Dec 4]. Available from: http://www.ahwo.gov.au/documents.

6. Grancher U, Muehlbauer T, Gollhofer A, Kressig RW, Zahner L. An intergenerational approach in the promotion of balance and strength for fall prevention- a mini review. Gerontology. 2011;57:304-15. [PMID:20720401]

7. National Health Survey: Summary of Results, Australia, 2004-2005 [Internet]. Australian Bureau of Statistics. c2006 [cited 2013 Dec 4]. Available from: http://www.abs.gov.au.

8. Banks M, Ash S, Bauer J, Gaskill D. Prevalence of malnutrition in adults in Queensland public hospitals and residential aged care facilities. Nutr Diet. 2007;64:172-8.

9. Gaskill D, Black LJ, Hassall S, et al. Malnutrition prevalence and nutrition issues in residential aged care facilities. Australas J Ageing. 2008;27:189-94. [PMID:19032620]

10. Partridge C, Johnston M, Morris L. Disability and health: perceptions of a sample of elderly people. Physiother Res Int. 1996;1:17-29. [PMID:9238720]

11. Gusi N, Adsuar JC, Corzo H, del Pozo-Cruz B, Olivares PR, Parraca JA. Balance training reduces the fear of falling and improves dynamic balance and isometric strength in institutionalised older people: a randomised trial. Journal of Physiotherapy. 2012;58:97-104. [PMID:22613239]

12. Hasselgren $L$, Olsson L, Nyberg $L$. Is leg muscle strength correlated with functional balance and mobility among inpatients in geriatric rehabilitation? Arch Gerontol Geriat. 2011;52:e220-5. [PMID:21156325]

13. Howe TE, Rochester L, Neil F, Skelton DA, Ballinger $C$. Exercise for improving balance in older people. Cochrane Database of Systematic Reviews. 2011;11. Art. No.: CD004963. [PMID:22071817] 
14. Gaskill $D$, Isenring EA, Black LJ, et al. Maintaining nutrition in aged care residents with a train-the-trainer intervention and nutrition coordinator. J Nutr Health Ageing. 2009;13:913-7. [PMID:19924353]

15. Grieger JA, Nowson CA, Jarman HF, Malon R, Ackland LM. Multivitamin supplementation improves nutritional status and bone quality in aged care residents. Eur J Clin Nutr. 2009;63:558-65. [PMID:18043700]

16. Milne AC, Potter J, Vivanti A, Avenell A. Protein and energy supplementation in elderly people at risk from malnutrition. Cochrane Database of Systematic Reviews. 2009;2. Art. No.: CD003288. [PMID:19370584]

17. Hobbs C, Dean C, Higgs J, Adamson B. Physiotherapy students' attitudes towards and knowledge of older people. Aust $J$ Physiother. 2006;52:115-9.[PMID:16764548]

18. My Aged Care [Internet]. Australian Government, Department of Social Services. c2013 [cited 2013 Dec 4]. Available from: http://www.myagedcare.gov.au.

19. Lekkas P, Larsen T, Kumar S, Grimmer K, Nyland L, Chipchase L, et al. No model of clinical education for physiotherapy students is superior to another: a systematic review. Aust J Physiother. 2007;52:19-28. [PMID:17326735] 


\section{APPENDIX A}

Allied Health Professional Placements in Aged Care: Capacity, Attitudes and Support Needs Allied Health Professional Survey

\section{Section 1: Information about you}

1. What is your gender?

$\square$ female male

2. What is your profession? (tick one)

$\square$ Physiotherapist

Dietitian, please indicate your role (tick one or both as applicable): Food Services

Clinical

3. How long ago did you complete your entry level professional qualification? (tick one)
$\square$ Less than 1 year
Between 1 and 4 years
Between 5 and 10 years
Between 11 and 15 years
Greater than 15 years

\section{Section 2: Student supervision}

The questions in the following section relate to supervision of either physiotherapy or dietetics students. Please answer with respect to your professional background.

4. Do you supervise students in your current position? (tick one)
$\square$ No $\quad$ Go to Q6
$\square$ Yes

5. If yes, what type of placements have you supervised? (tick any that apply)

$\square$ Full time block placements

$\square$ Part time/sessional

6. If you stated you do not supervise students at present, what are some of the reasons that you do not currently supervise students?

7. If you stated you do not supervise students at present, do you feel your aged care facility(s) has the scope to provide Allied Health Professional student placements? (tick one)

$\square$ No $\square$ Yes

8. Have you ever supervised students in previous positions? (tick one)
$\square$ No
$\square$ Yes 


\section{Section 3: Student placements in aged care}

9. Do you think there are advantages for Allied Health Professional students in undertaking placements in the aged care setting? (tick one)

$\square$ No (go to Q10) $\square$ Yes

If yes please briefly describe the advantages

10. Do you think there are disadvantages for entry level Allied Health professional students in undertaking placements in the aged care setting? (tick one)

$\square$ No (go to Q11) $\square$ Yes

If yes please briefly describe the disadvantages.

11. Do you think there are any barriers to entry level Allied Health professional students in undertaking placements in the aged care setting? (tick one)

$\square$ No (go to Q12)

$\square$ Yes

If yes please briefly describe the barriers

\section{Section 4: Training and support needs}

12 What additional support/training/resources do you think would be useful to facilitate Allied Health Professional student placements in the aged care setting?

Support

Training

Resources

\section{Section 5: General comments}

13. Do you have any further comments about entry level Allied Health professional student placements in the aged care setting?

Thank you very much for your time and your participation in this survey 


\section{APPENDIX B}

\section{Allied Health Professional Placements in Aged Care: Capacity, Attitudes and Support Needs Aged Care Manager Survey}

Section 1: Information about you
1. Gender
$\square$ female
$\square$ male

2. Professional background (describe - health / business / managerial / other)

$\square$ Health professional

$\square$ Other, please specify:

3. Years in aged care management positions (number of years):

Section 2: Student placements in aged care settings

7. Do you currently have entry level health professional students in your facility? (tick one)
$\square$ No
$\square$ Yes

8. If yes what profession(s)?

$\square$ Medicine

$\square$ Nursing

$\square$ Physiotherapy

$\square$ Dietetics

Other Allied Health, please specify:

9. If no, what are some of the reasons you do not have students in your facility?

10 Do you think there are advantages for Allied Health Professional students in undertaking placements in the aged care setting? (tick one) $\quad \square$ No (go to Q11) $\square$ Yes

Please briefly describe the advantages

11. Do you think there are disadvantages for Allied Health Professional students in undertaking placements in the aged care setting? (tick one) $\square$ No

Please briefly describe the disadvantages

12. Do you think there are any barriers to entry level Allied Health professional students in undertaking placements in the aged care setting? (tick one) $\square$ No $\quad \square$ Yes

Please briefly describe the barriers (may need to prompt to cover both specific issues relating to their facility and more general issues eg funding)

\section{Section 4: Training and support needs}

13. Do you feel your facility has the scope to provide Allied Health Professional student placements? (tick one)

$\square$ No $\square$ Yes

14. Please outline reasons for your answer 
15. What additional support/training/resources do you think would be useful to facilitate entry level Allied Health professional student placements in your aged care facility?

\section{Section 5: General comments}

15. Do you have any further comments about level Allied Health Professional student placements in the aged care setting?

Thank you very much for your time and your participation in this survey 